\title{
The Stimulatory Effect of the Non-metabolized Sugar 3-O-Methyl Glucose on the Conversion of Mannitol and Arabitol to Polysaccharide and Other Insoluble Compounds in the Fungus Dendryphiella salina
}

\author{
By D. H. JENNINGS AND SHIRLEY AUSTIN \\ Department of Botany, The University of Liverpool, Liverpool, L69 3 BX
}

(Received I6 August 1972; revised 28 November 1972)

SUMMAR Y

\begin{abstract}
When 3-O-methyl glucose is actively transported into the fungus Dendryphiella salina metabolizable soluble carbohydrate is converted into polysaccharide and other insoluble material such that the total soluble carbohydrate concentration remains constant. Uptake of $3-O$-methyl glucose from $\mathrm{I} \cdot \mathrm{O} \mathrm{mm}$ solution is inhibited by equimolar glucose, fructose, mannitol or arabitol and by potassium acetate, both ionic species being involved. The results are discussed in relation to the control of hyphal osmotic pressure.
\end{abstract}

\section{INTRODUCTION}

The kinetics of glucose transport into cells are often best studied by using those analogues of glucose which are not metabolized. These analogues are used because uptake can be assayed radiochemically and active transport can be demonstrated unequivocally. Usuaily the amount of the analogue which has entered the cell is determined. If the analogue can be obtained with a high specific activity, the relationship between rate of uptake and the external concentration can be determined with a considerable degree of accuracy because the experimental period can be short enough to minimize changes of concentration in the medium. However, because the analogue is not metabolized, it is often assumed that its presence inside the cell is without effect on metabolism. This paper reports data for the marine hyphomycete Dendryphiella salina, demonstrating the incorrectness of this assumption.

Detailed information about the carbohydrate metabolism of Dendryphiella salina has been provided already (Allaway \& Jennings, I970 $b$; Holligan \& Jennings, I972 $a, b, c$, I973). The major soluble carbohydrates are mannitol and arabitol, the relative amounts being determined by the form in which the nitrogen is supplied to the external medium.

\section{METHODS}

Organism and media. Dendryphiella salina Nicot \& Pugh was maintained in culture and grown for experimental purposes as described by Allaway \& Jennings (I970a).

Experimental procedure. In all but one experiment (see Table 6) mycelial suspensions $(25 \mathrm{ml})$ were incubated at $20{ }^{\circ} \mathrm{C}$ in open $\mathrm{I} 50 \mathrm{ml}$ boiling tubes. Aeration was via capillary tubes and at a rate sufficient to keep the suspension well stirred. When flasks were used for pretreatment of the mycelium, the same method of aeration was used. The procedures for washing mycelium and obtaining dry weights have been described by Allaway \& Jennings $(1970 a)$. 
3-O-Methyl glucose in the external medium. Determined by method of Dubois et al. (1956). - Mycelial carbohydrate (including 3-O-methyl glucose) extraction and analysis. As described by Holligan \& Jennings ( $1972 a$ ).

Labelled compound and assay of radioactivity. $3-O-$ Methyl- $\alpha-\mathrm{D}$-glucose- ${ }^{14} \mathrm{C}(\mathrm{U})$ and $\mathrm{D}-$ mannitol- $-{ }^{14} \mathrm{C}$ were obtained from the Radiochemical Centre, Amersham, Buckinghamshire. The level of radioactivity was determined with a Tricarb 3320 scintillation counter with Io ml Bray's medium/vial. Up to I $\mathrm{ml}$ of all solutions, except those containing $\mathrm{KOH}$, were added directly to the medium. $\mathrm{KOH}$ samples were added on $1 \cdot 7 \mathrm{~cm}^{2}$ filter paper. In all instances, the appropriate blanks were counted.

Ratio of intracelluler water/dry weight. This was taken as 2.54 (Slayman \& Tatum, I964). Results. Except in Table 6, results are the mean of three replicates \pm standard error.

\section{RESULTS}

When Dendryphiella salina was presented with $3-O$-methyl glucose $\left[\mathrm{U}-{ }^{14} \mathrm{C}\right]$ at $6 \mathrm{~mm}$ for $45 \mathrm{~min}$ in a Gilson respirometer, all the radioactivity was recovered from the medium and the ethanol-soluble fraction. There was no detectable radioactivity in the carbon dioxide produced or in the ethanol insoluble material. The radioactivity in the ethanol extract behaved as $3-O$-methyl glucose during chromatography. There was no change in the rate of oxygen uptake $(8.9 \mu \mathrm{l} / \mathrm{mg}$ dry $w \mathrm{t} / \mathrm{h})$ or carbon dioxide evolution $(5.2 \mu \mathrm{l} / \mathrm{mg} \mathrm{dry} \mathrm{wt} / \mathrm{h})$ after tipping the sugar from the side-arm.

3-O-Methyl glucose accumulated in the mycelium over a 25 -fold range of concentration of sugar in the external medium (Table I).

When the levels of the major soluble carbohydrates within the mycelium after $5 \mathrm{~h}$ in the presence of a range of concentrations of the $3-O$-methyl glucose in the external medium were determined, the uptake of the sugar was found to increase with external concentration up to I mM (Table 2). The absorption of 3-O-methyl glucose was accompanied by a drop in the mycelial levels of mannitol, arabitol and glucose (in all other experiments the mycelial levels of glucose were always less than $0.010 \mu \mathrm{mol} / \mathrm{mg}$ dry wt; the cause of the high level in this experiment is not known). The fall of glucose level may be related to the fall in mannitol level, since there is a close metabolic relation between these two compounds (Holligan \& Jennings, 1972a). However, the total mycelial soluble carbohydrate concentration was similar for all treatments.

The uptake of 3-O-methyl glucose was inhibited by equimolar concentrations of glucose, fructose, mannitol or arabitol in the external medium (Table 3). Inhibition was still observed when the concentration of these compounds was a quarter that of the methyl glucose. It is difficult to put any order to the effectiveness of inhibition but arabitol seemed to be the least inhibitory. The total mycelial soluble carbohydrate content at the end of the experimental period was similar for all the treatments. The greater the internal level of $3-O$-methyl glucose, the lower were the levels of both mannitol and arabitol. It is not possible to say, in this instance, whether the change in level of mannitol and arabitol was attributable to 3-O-methyl glucose affecting metabolic events within the mycelium or inhibiting the transport of the metabolizable carbohydrate into the fungus.

These data for the interaction between glucose and 3-O-methyl glucose on the uptake of the latter and upon the level of soluble carbohydrates within the mycelium are confirmed in Table 4. The data also show that 3-O-methyl glucose caused a greater drop in the mycelial content of mannitol and arabitol, than that which occurred in the mycelium in distilled water. 
Table I. Internal concentration of 3-O-methyl glucose $\left[U^{14} C\right]$ after 3 h of exposure to a range of concentrations in the external medium

$\begin{array}{ccc}\begin{array}{c}\text { External } \\ \text { concentration } \\ (\mathrm{mmol} / \mathrm{l})\end{array} & \begin{array}{c}\text { Internal } \\ \text { concentration } \\ (\mathrm{mmol} / \mathrm{l})\end{array} & \begin{array}{c}\text { Internal/ } \\ \text { external } \\ \text { concentrations }\end{array} \\ 0.04 & 0.37 \pm 0.02 & 92.5 \\ 0 . \mathrm{I} & 7 \cdot 75 \pm 0.22 & 77 \\ \mathrm{I} \cdot 0 & 83.8 \pm 2.3 & 84\end{array}$

Table 2. The internal concentration ( $\mu$ mollmg dry wt) of major soluble carbohydrates after $5 \mathrm{~h}$ in media containing different concentrations of 3-O-methyl glucose

Initial

concentration

of 3-O-methyl

glucose in medium (M)

$\begin{array}{cc}\text { dium (M) } & \text { Mannitol } \\ - & 0.290 \pm 0.015 \\ 10^{-5} & 0.291 \pm 0.007 \\ 10^{-4} & 0.303 \pm 0.020 \\ 10^{-3} & 0.093 \pm 0.004 \\ 10^{-2} & 0.061 \pm 0.003 \\ 10^{-1} & 0.061 \pm 0.003\end{array}$

Arabitol
$0.089 \pm 0.001$
$0.093 \pm 0.008$
$0.075 \pm 0.002$
$0.051 \pm 0.003$
$0.035 \pm 0.002$
$0.036 \pm 0.007$

Glucose

3-O-Methyl glucose

Total
$0.192 \pm 0.027$
c. $163 \pm 0.013$
$0.132 \pm 0.020$
$0.116 \pm 0.006$
$0.117 \pm 0.006$
$0.111 \pm 0.004$

-
$0.001 \pm 0$
$0.027 \pm 0.007$
$0.264 \pm 0.006$
$0.251 \pm 0.012$
$0.303 \pm 0.048$

$0.571 \pm 0.043$
$0.548 \pm 0.028$
$0.537 \pm 0.049$
$0.524 \pm 0.019$
$0.461 \pm 0.023$
$0.511 \pm 0.062$

Table 3. The internal concentration ( $\mu$ mol/mg dry wt) of major soluble carbohydrates after $4.5 \mathrm{~h}$ in media containing either no added sugars or $\mathrm{I} \cdot 0 \mathrm{m \textrm {M } - 3 - O}$-methyl glucose with or without metabolizable carbohydrates

$\begin{array}{lcccc}\begin{array}{l}\text { Metabolizable carbohydrate } \\ \text { 3-O-Methyl glucose absent medium }\end{array} & \text { Mannitol } & \text { Arabitol } & \text { 3-O-Methyl glucose } & \text { Total } \\ \text { - } & 0.181 \pm 0.018 & 0.112 \pm 0.002 & - & 0.293 \pm 0.020 \\ \text { I.0 mM-3- } O \text {-methyl glucose present } & & & \\ \text { - } & 0.068 \pm 0.001 & 0.071 \pm 0.007 & 0.188 \pm 0.012 & 0.327 \pm 0.020 \\ 0.25 \text { mM-glucose } & 0.090 \pm 0.002 & 0.100 \pm 0.003 & 0.103 \pm 0.019 & 0.293 \pm 0.024 \\ \text { I.0 mM-glucose } & 0.121 \pm 0.003 & 0.135 \pm 0.009 & 0.041 \pm 0.014 & 0.297 \pm 0.026 \\ 0.25 \text { mM-fructose } & 0.076 \pm 0.003 & 0.099 \pm 0.005 & 0.077 \pm 0.017 & 0.252 \pm 0.025 \\ \text { I.0 mM-fructose } & 0.132 \pm 0.005 & 0.110 \pm 0.004 & 0.022 \pm 0.024 & 0.264 \pm 0.033 \\ 0.25 \text { mM-mannitol } & 0.085 \pm 0.005 & 0.085 \pm 0.003 & 0.063 \pm 0.009 & 0.233 \pm 0.017 \\ \text { I.0 mM-mannitol } & 0.119 \pm 0.003 & 0.087 \pm 0.003 & 0.075 \pm 0.023 & 0.281 \pm 0.029 \\ 0.25 \mathrm{mM} \text {-arabitol } & 0.064 \pm 0 & 0.135 \pm 0.003 & 0.090 \pm 0.024 & 0.289 \pm 0.027 \\ \text { I.0 mM-arabitol } & 0.060 \pm 0.003 & 0.168 \pm 0.001 & 0.129 \pm 0.067 & 0.357 \pm 0.070\end{array}$

Table 4. The internal concentration ( mollmg dry wt) of major soluble carbohydrates before and after exposure to media containing either no added sugars or $\mathrm{I} \cdot 0 \mathrm{~m} \mathrm{M}-3-O-m e t h y l ~ g l u c o s e$ in the presence or absence of various concentrations of glucose

Concentration of glucose in medium (mM)

Initial values

$$
\text { Mannitol }
$$

Arabitol

$$
\begin{aligned}
& \text { 3-O-Methyl } \\
& \text { glucose }
\end{aligned}
$$

Total

3-O-Methyl glucose absent from the medium

$$
0.172 \pm 0.007
$$

$0.065 \pm 0.001$

$$
\text { - }
$$

$$
0.237 \pm 0.008
$$

3-O-Methyl glucose present

$$
\begin{aligned}
& 0.147 \pm 0.005 \\
& 0.054 \pm 0.002 \\
& 0.106 \pm 0.003 \\
& 0.199 \pm 0.007 \\
& 0.221 \pm 0.004
\end{aligned}
$$

$0.059 \pm 0.001$

$0.037 \pm 0.001$

$0.057 \pm 0.001$

$0.061 \pm 0.001$

$0.059 \pm 0.00 \mathrm{I}$

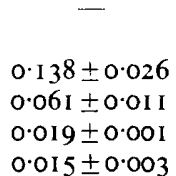

$0 \cdot 206 \pm 0 \cdot 006$

$0.229 \pm 0.029$

$0.224 \pm 0.015$

$0.279 \pm 0.009$

$0.295 \pm 0.008$ 
Another experiment showed the effects of three treatments - glucose, 3-O-methyl glucose (each at $\mathrm{I} \cdot 0 \mathrm{~mm}$ ) and distilled water - on the mycelial level of mannitol available and polysaccharide hydrolysable by $\mathrm{I} \cdot 5 \mathrm{~N}$-sulphuric acid (Table 5 ). The initial levels of soluble carbohydrate were relatively high and there was a drop to a level which appears to be independent of the treatment. The level of polysaccharide hydrolysed by $\mathrm{I} \cdot 5 \mathrm{~N}$-sulphuric acid rose in the 3-O-methyl glucose treatment, remained the same with glucose but fell in distilled water. The difference at the end of $3 \mathrm{~h}$ between the level in the mycelium which had been in distilled water and that which had been in $3-O$-methyl glucose was $0.2 \mu \mathrm{mol} / \mathrm{mg}$ dry wt. This value, which is about two-thirds of the amount of 3-O-methyl glucose taken into mycelium, allows one to suggest that the reduced level of soluble metabolizable carbohydrate found after treatment with 3-O-methyl glucose might in part be a consequence of their conversion to polysaccharide. However, only $50 \%$ of the reduction can be accounted for by such a conversion, so $3^{-O}-$-methyl glucose must accelerate the conversion of soluble carbohydrates to compounds other than polysaccharide hydrolysable with $1 \cdot 5 \mathrm{~N}$-sulphuric acid.

The end products of the metabolic processes stimulated by $3-O$-methyl glucose were also investigated by using radioactive tracer (Table 6). Mycelium pretreated with mannitol $\left[\mathrm{I}^{-14} \mathrm{C}\right]$ was left for $3 \mathrm{~h}$ to allow equilibration of the label, the medium containing calcium chloride to minimize loss of radioactive compounds from the hyphae (Allaway \& Jennings, $1970 \mathrm{~b}$ ). During this period, radioactivity moved from the soluble fraction to carbon dioxide and insoluble material, both that hydrolysable by $\mathrm{I} \cdot 5 \mathrm{~N}-\mathrm{H}_{2} \mathrm{SO}_{4}$ and that resistant to hydrolysis, some of which is likely to have been polysaccharide. In a subsequent $3 \mathrm{~h}$ period, the rate of loss into carbon dioxide was very much reduced, but radioactivity moved into the fraction hydrolysable with $\mathrm{I} \cdot 5 \mathrm{~N}$-sulphuric acid from that resistant to hydrolysis. There was little change in the amount of radioactivity in ethanol-soluble fraction. On the other hand, the addition of $3-O$-methyl glucose to the medium caused a movement of nearly $45 \%$ of the radioactivity from the ethanol-soluble fraction into insoluble material.

Romano \& Kornberg (I969) showed that uptake of 2-deoxy-D-glucose by Aspergillus nidulans was inhibited by acetate. The effects of acetate on the uptake of 3-O-methyl glucose by Dendryphiella salina provides a useful point of comparison between the transport systems in the two fungi. In $D$. salina uptake of 3-O-methyl glucose was inhibited by $100 \mathrm{mM}-$ potassium acetate (Table 7). Calcium chloride ( $10 \mathrm{~mm}$ ) has an ameliorating effect but the amount of sugar absorbed is still lower than that when chloride ions were in the medium instead of acetate.

Allaway \& Jennings (I970a) have shown that calcium, by maintaining membrane integrity, prevents monovalent cations from inhibiting glucose uptake and utilization by Dendryphiella salina. An experiment was designed to show that essentially the same holds for the effect of monovalent cations upon the uptake of 3-O-methyl glucose. When mycelium containing $3-O$-methyl glucose was put in solutions containing the radioactive sugar and either $200 \mathrm{~mm}$-sodium or potassium chlorides with or without $10 \mathrm{~mm}$-calcium chloride, uptake was lower in the solutions containing only sodium or potassium chlorides than when calcium was also present (Table 8). Parallel measurements of loss of previously absorbed 3-O-methyl glucose (in this instance radioactive) show that the decreased uptake was accompanied by increased loss of the sugar and vice versa. The reasons for the relatively high value for uptake of $3-O$-methyl glucose in distilled water are not clear 
Table 5. Changes in ethanol-soluble carbohydrate (mannitol, arabitol and 3-O-methyl glucose) and carbohydrate hydrolysable by $\mathrm{I} \cdot 5 \mathrm{~N}-$ sulphuric acid brought about by glucose or 3-Omethyl glucose

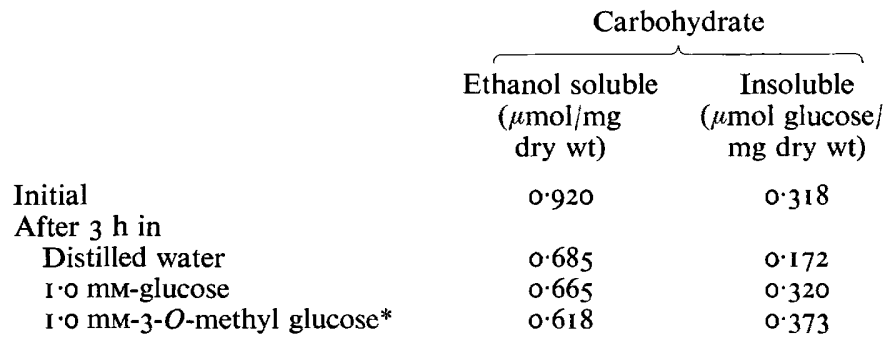

* Amount 3-O-methyl glucose absorbed: $0.329 \mu \mathrm{mol} / \mathrm{mg}$ dry wt.

Table 6. The effect of 3-O-methyl glucose on distribution of radioactivity between various fractions

\begin{abstract}
Mycelium (0.423 $\mathrm{g}$ dry wt) was pre-incubated for $3 \mathrm{~h}$ in $70 \mathrm{ml} 2 \cdot 5 \times 1 \mathrm{O}^{-2} \mathrm{M}$-mannitol $\left[\mathrm{I}-{ }^{14} \mathrm{C}\right](0 \cdot 14 \mu \mathrm{Ci} /-$ $\mathrm{ml}$ ) in a $250 \mathrm{ml}$ conical flask, then separated from the medium and thoroughly washed with distilled water. Mycelium was then dispensed into Gilson flasks and suspended in $3.0 \mathrm{ml} \mathrm{IO}^{-2} \mathrm{M}$-calcium chloride. Flasks were shaken at $20^{\circ} \mathrm{C}$ for $6 \mathrm{~h}$; in the appropriate instance after $3 \mathrm{~h} 3-O$-methyl glucose was tipped from the side arm to give $\mathrm{I} \cdot 0 \mathrm{~mm}$. At the end of the experiment, the centre well of the flasks was washed out twice with $0.2 \mathrm{ml}$ potassium hydroxide, the solution being removed with paper squares. Results means of two values.
\end{abstract}

\begin{tabular}{|c|c|c|c|c|c|}
\hline & & Radi & tivity (c.p.m./mg & dry wt) & \\
\hline Time of measurement & Medium & $\begin{array}{l}\text { Ethanol } \\
\text { soluble } \\
\text { fraction }\end{array}$ & 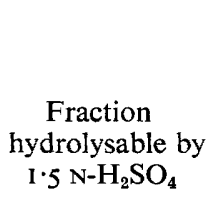 & $\begin{array}{c}\text { Material } \\
\text { resistant to } \\
\text { hydrolysis } \\
\text { [initial- } \Sigma \\
\text { other } \\
\text { fractions] }\end{array}$ & $\begin{array}{c}\mathrm{CO}_{2} \\
\text { trapped } \\
\text { by } \mathrm{KOH}\end{array}$ \\
\hline Initial & - & $240 I$ & 583 & 141 & \\
\hline $3 \mathrm{~h}$ & 16 & 1229 & 886 & 691 & 303 \\
\hline $6 \mathrm{~h}$ & 99 & I I 28 & I 245 & 294 & 357 \\
\hline $\begin{array}{l}3 \mathrm{~h}+3 \mathrm{~h} \text { in } 3-O \text {-methyl } \\
\text { glucose }\end{array}$ & 80 & 702 & $155^{8}$ & 460 & 325 \\
\hline
\end{tabular}

Table 7. Effect of potassium acetate in the presence and absence of calcium chloride on the uptake of 3-O-methyl glucose (determined by loss from medium) from a $\mathrm{I} \cdot \mathrm{O} \mathrm{mm}$ solution over $5 h$

Treatment

100 mM-K acetate

IoO mM-K acetate + $10 \mathrm{~mm}-\mathrm{CaCl}_{2}$

$100 \mathrm{~mm}-\mathrm{KCl}+$ Io $\mathrm{mm} \mathrm{CaCl}_{2}$

Io mM-K acetate + IO mM-CaCl Io $\mathrm{mm}-\mathrm{KCl}+10 \mathrm{~mm}-\mathrm{CaCl}_{2}$
Uptake in $\mu \mathrm{mol} / \mathrm{mg}$ dry wt

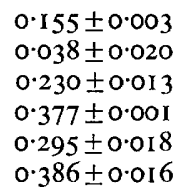




\section{Table 8 . The effect of various salt treatments on the uptake and loss of 3-O-methyl glucose $\left[U_{-14} C\right]$ over $3 \mathrm{~h}$}

Two samples of mycelium of about $\mathrm{I} \cdot 6 \mathrm{~g}$ (dry wt) incubated for $3 \mathrm{~h}$ in $600 \mathrm{ml} 4 \times 10^{-3} \mathrm{~mm}-3-O$ methyl glucose in 1 l conical flask. One solution contained $0.04 \mu \mathrm{Ci} / \mathrm{ml}$ radioactivity and the mycelium absorbed an amount equivalent to $1.47 \mathrm{nmol} / \mathrm{mg}$ dry wt. After $3 \mathrm{~h}$ the mycelium was separated from the medium, thoroughly washed and resuspended in distilled water. Samples were dispensed into tubes containing the appropriate ions and $4 \times 10^{-3} \mathrm{~mm}-3-O$-methyl glucose, radioactive $(0.04 \mu \mathrm{Ci} / \mathrm{ml})$ for non-radioactive mycelium and vice versa.

\begin{tabular}{|c|c|c|}
\hline Treatment & $\begin{array}{l}\text { Uptake of } 3-O \text {-methyl } \\
\text { glucose } \mathrm{nmol} / \mathrm{mg} \text { dry wt }\end{array}$ & $\begin{array}{r}\text { Loss of radioact } \\
\% \text { absorbed in } \mathrm{p} \\
\text { ment perio }\end{array}$ \\
\hline- & $4 \cdot 7 \pm 0 \cdot 2$ & $13 \cdot I \pm C$ \\
\hline$+200 \mathrm{~mm}-\mathrm{NaCl}$ & $3 \cdot 2 \pm 0 \cdot 1$ & $36 \cdot 5 \pm 0$ \\
\hline$+200 \mathrm{mM}-\mathrm{NaCl}+\mathrm{I} 0 \mathrm{mM}-\mathrm{CaCl}_{2}$ & $3.9 \pm 0.2$ & $23.9 \pm \mathrm{I}$ \\
\hline$+200 \mathrm{~mm}-\mathrm{KCl}$ & $2 \cdot 3 \pm 0 \cdot 0$ & $36 \cdot 5 \pm 2$ \\
\hline$+200 \mathrm{~mm}-\mathrm{KCl}+10 \mathrm{~mm}-\mathrm{CaCl}_{2}$ & $3 \cdot 3 \pm 0 \cdot 1$ & $20 \cdot 8 \pm$ \\
\hline$+10 \mathrm{mM}^{-\mathrm{CaCl}}{ }_{2}$ & $3.9 \pm 0.2$ & $\mathrm{I} 3 \cdot 2 \pm \mathrm{C}$ \\
\hline
\end{tabular}

\section{DISCUSSION}

There is no evidence that 3-O-methyl is metabolized by Dendryphiella salina, yet entry of this sugar into the mycelium causes an increased rate of metabolism of those soluble carbohydrates already present. This increased rate of metabolism is not ar companied by any change in the rate of respiration. Chemical analysis has shown conversion of soluble carbohydrate to polysaccharide is one of the processes increased in rate by $3-O$-methyl glucose. The results from the experiment with radioactive tracer confirm this, though these latter results should be viewed with some caution since we have no information about those compounds in the ethanol-soluble fraction which became labelled.

A striking feature of the data is the great similarity of the mycelial concentration of soluble carbohydrates at the end of a period of exposure either to 3- $O$-methyl glucose or to a range of carbohydrates which can be metabolized. The simplest hypothesis is that the transport of each molecule of sugar into the mycelium is accompanied by the concomitant conversion of either a mannitol or an arabitol molecule into polysaccharide or some other insoluble compound. Of the two sugar alcohols, mannitol is the more likely candidate for direct involvement since, from the few results obtained (Table 9), there appears to be a simple relationship between 3-O-methyl glucose uptake and mannitol level, whereas no such relationship appears to exist with arabitol.

The ability of the mycelium to maintain a constant concentration of soluble carbohydrates whilst also absorbing carbohydrates from the external medium will mean that there is little fluctuation of the hyphal osmotic pressure. Inadequate regulation of this can lead to the bursting of hyphae or changes in their morphology (Robertson, 1959). It must be pointed out that the information presented here refers to only one aspect of the problem of the control of hyphal osmotic pressure in Dendryphiella salina. Thus, when mycelium is exposed to varying concentrations of sea water and $0.27 \mathrm{~mm}$-glucose, increasing amounts of mannitol and arabitol are produced in the mycelium as the medium becomes more saline. The increase in the mycelial content of these two sugar alcohols is a major contribution to the adjustment of the hyphal osmotic pressure, so that the correct differential of water potential is maintained between the mycelium and the external medium (Jennings, 1973).

It is not unreasonable to conclude, from the marked inhibition of $3-O$-methyl glucose 
Table 9. The relationship between the amount of 3-O-methyl glucose absorbed and the initial internal concentration of mannitol and arabitol

\begin{tabular}{|c|c|c|c|c|c|}
\hline \multirow{3}{*}{$\begin{array}{l}\text { Table from } \\
\text { which data } \\
\text { abstracted* }\end{array}$} & & & \multirow{3}{*}{$\begin{array}{l}\text { 3-O-Methyl } \\
\text { glucose } \\
\text { absorbed }\end{array}$} & \multicolumn{2}{|c|}{ Ratio } \\
\hline & \multicolumn{2}{|c|}{ Initial concentration } & & \multirow{2}{*}{$\begin{array}{l}\text { 3-O-Methyl } \\
\text { glucose: } \\
\text { mannitol }\end{array}$} & \multirow{2}{*}{$\begin{array}{c}\text { 3-O-Methyl } \\
\text { glucose: } \\
\text { arabitol }\end{array}$} \\
\hline & Mannitol & Arabitol & & & \\
\hline 4 & 0.172 & 0.065 & 0.138 & 0.80 & $2 \cdot 24$ \\
\hline $3^{\dagger}$ & 0.181 & $C \cdot 112$ & O. I 88 & $1 \cdot 04$ & I. 68 \\
\hline $2 \dagger$ & $0 \cdot 290$ & 0.089 & 0.264 & 0.91 & $2 \cdot 97$ \\
\hline New data & $0.42 \mathrm{I}$ & 0.235 & 0.329 & $0 \cdot 78$ & $I \cdot 40$ \\
\hline
\end{tabular}

uptake by glucose, fructose, mannitol and arabitol, that the same system is involved in the transport of all these compounds. But much more quantitative information, particularly about how 3-O-methyl glucose affects the uptake of the hexoses and the polyols, is needed to substantiate this. If Dendryphiella salina is like Neurospora crassa in possessing two glucose-transport systems (Scarborough, 1970 a,b), the bulk of the information presented here must refer to the low affinity system, since in $N$. crassa this system is operative over the range of concentrations used in this study. At first sight, the system appears to be like that of Aspergillus niger which is responsible for the uptake of glucose and 2-deoxy-D-glucose. However, this comparison needs to be made with caution, since the relevant information for $A$. niger does not take into account the effect of monovalent cations on the permeability of the hyphae. The reduced uptake of 2-deoxy-D-glucose brought about by the presence of IOO mM-sodium acetate is as likely to be caused by the sodium as by the acetate ions. Further, the reduction in level of phosphorylated compounds in $A$. niger observed with sodium acetate could be due to loss into the medium brought about by sodium ions; this has been found for excised beech mycorrhiza (Jennings, I964).

We are not sure why acetate inhibits the uptake of 3-O-methyl glucose by Dendryphiella salina. Conceivably, acetyl-coenzyme A produced from the acetate which is assimilated may be the inhibitory agent (Morgan \& Kornberg, I969). On the other hand, since acetate assimilation in D. salina leads to accumulation of mannitol and arabitol (Holligan \& Jennings, 1973) it is conceivable that these latter compounds, particularly mannitol, may be bringing about the inhibition. We point out this possibility, because the experiments with acetate differ from the others in that the uptake of 3-O-methyl glucose was measured over a period when sugar alcohols were being continuously synthesized from an exogenous carbon source.

A great deal more work is required to determine the metabolic events which are taking place when 3-O-methyl glucose is transported into the mycelium of Dendryphiella salina. We appreciate the data are inadequate for detailed mechanistic interpretation and work is in progress to help rectify this. Nevertheless, the present data require presentation since they draw attention to metabolic events which occur during the active transport of a nonmetabolizable sugar and which do not seem to have been anticipated by others making similar studies.

We thank Mr M. Bewick and Mr Y-B. Ho for their help in this investigation. We are indebted to S.R.C. for financial support. 


\section{REFERENCES}

Allaway, A. E. \& Jennings, D. H. (1970a). The influence of cations on glucose uptake by the fungus Dendryphiella salina. New Phytologist 69, 567-579.

Allaway, A. E. \& Jennings, D. H. (1970 $b$ ). The influence of cations on glucose transport and metabolism by, and the loss of sugar alcohols from, the fungus Dendryphiella salina. New Phytologist 69, 58I-593.

Dubois, M., Gilles, K. A., Hamiton, J. K., Rebers, P. A. \& Smith, F. (I956). Colorimetric method for the determination of sugars and related substances. Analytical Chemistry 28, 350-356.

Holligan, P. M. \& Jennings, D. H. (1972a). Carbohydrate metabolism in the fungus Dendryphiella salina. I. Changes in the levels of soluble carbohydrates during growth. New Phytologist 7I, 569-582.

Holligan, P. M. \& Jennings, D. H. (1972 b). Carbohydrate metabolism in the fungus Dendryphiella salina. II. The influence of different carbon and nitrogen sources on the accumulation of mannitol and arabitol. New Phytologist 7I, 583-594.

Holligals, P. M. \& JenningS, D. H. (1972c). Carbohydrate metabolism in the fungus Dendryphiella salina. III. The effect of the nitrogen source on the metabolism of $\mathrm{I}^{14} \mathrm{C}$ and $6-{ }^{14} \mathrm{C}$ glucose. New Phytologist 7I, III9-II33.

Holligan, P. M. \& Jennings, D. H. (1973). Carbohydrate metabolism in the fungus Dendryphiella salina. IV. Synthesis of mannitol and arabitol from acetate and succinate. New Phytologist (in the Press).

JENNINGS, D. H. (1964). The effect of cations on the absorption of phosphate by beech mycorrhizal roots. New Phytologist 63, 348-357.

JENNINGS, D. H. (1973). Cations and filamentous fungi: Invasion of the sea and hyphal functioning. In Ion Transport in Plants. Edited by W. P. Anderson. London: Academic Press (in the Press).

Morgan, M. J. \& Kornberg, H. L. (I969). Regulation of sugar accumulation by Escherichia coli. FEBS Letters 3, 53-56.

ROBERTSON, N. R. (1959). Experimental control of hyphal branching and branch form in hyphomycetous fungi. Journal of the Linnean Society of London 56, 207-2 I I.

Romano, A. H. \& Kornberg, H. L. (1969). Regulation of sugar uptake by Aspergillus nidulans. Proceedings of the Royal Society B 173, 475-490.

SCARBOROUGH, G. A. (1970a). Sugar transport in Neurospora crassa. Journal of Biological Chemistry 245, $1694-1698$.

SCARBorough, G. A. (1970 b). Sugar transport in Neurospora crassa. II. A second glucose transport system. Journal of Biological Chemistry 245, 3985-3987.

Slayman, C. W. \& Tatum, E. L. (1964). Potassium transport in Neurospora. I. Intracellular sodium and potassium concentrations, and cation requirements for growth. Biochemica et biophysica acta 88, $578-592$. 